\title{
Continuous planning: an important aspect of agile and lean development
}

\section{Tanja Suomalainen*, Raija Kuusela and Maarit Tihinen}

VTT Technical Research Centre of Finland Ltd, Kaitoväylä 1, P.O. Box 1100, FI-90571 Oulu, Finland

Email: Tanja.Suomalainen@vtt.fi

Email: Raija.Kuusela@vtt.fi

Email: Maarit.Tihinen@vtt.fi

*Corresponding author

\begin{abstract}
Continuous planning is a relatively new and not yet fully studied field of research, especially from the perspective of agile and lean development organisations. To augment the knowledge in this field, this article presents both a literature review and empirical findings from three case studies that reveal how companies conduct continuous planning. The results indicate that continuous planning is not commonly adopted and applied throughout these organisations and that it currently involves only a certain kind of planning (e.g., release planning). The results of this study bring to light that the main elements of continuous planning (i.e., organisational, strategic and business planning) are tightly related to each other and thus should be considered when companies seek to improve their planning processes and practices. The importance of continuous planning will only increase dramatically in turbulent business environments that include ever shorter planning cycles and the need to improve transparency and knowledge-sharing in organisations.
\end{abstract}

Keywords: continuous planning; strategic planning; business planning; roadmapping; agile; lean; leagile; software development.

Reference to this paper should be made as follows: Suomalainen, T., Kuusela, R. and Tihinen, M. (2015) 'Continuous planning: an important aspect of agile and lean development', Int. J. Agile Systems and Management, Vol. 8, No. 2, pp.132-162.

Biographical notes: Tanja Suomalainen received her MSc (2006) degree from the University of Oulu, Department of Information Processing Science. She has worked at VTT (Technical Research Centre of Finland Ltd) since 2005. She began her career as a research trainee and upon graduation became a Research Scientist. Currently, she is also a PhD student in the Faculty of Information Processing Science at the University of Oulu, Finland. Her research interests include continuous planning rating, particularly strategic and business planning, product planning, roadmapping and release planning, as well as agile and lean software development methods and practices.

Raija Kuusela has almost 30 years of experience in the ICT sector. She has been working as a Senior Scientist at VTT since 2009. Prior to this, she worked at Nokia for 14 years in several roles, including software development roles, engineering manager, quality manager, scrum master and product owner. Before her career at Nokia, she worked with other software-intensive 
companies for 13 years in software development roles. She received her $\mathrm{PhD}$ in Industrial Engineering and Management from the University of Oulu, Finland, in 2007.

Maarit Tihinen is a Senior Scientist at VTT. She graduated in 1991 from the Department of Mathematics at the University of Oulu. She worked as a teacher (mainly mathematics and computer sciences) at the University of Applied Sciences before coming to VTT in 2000. She wrote her secondary subject thesis in 2001 and received her PhD in 2014 in Information Processing Science from the University of Oulu, Finland. She has worked in several national and international research and customer projects and written scientific publications both for international software engineering conferences and journals. Her research interests include various topics related to software processes, global software development, measurement and metrics and quality management.

\section{Introduction}

Since the mid-1990s, agile methods have assisted software-intensive companies to achieve targets such as decreasing lead times and improving the quality of products. It has been claimed that agile development methods increase the ability of software organisations to respond to dynamic market changes (Highsmith, 2002; Kettunen, 2009). Alternatively, business agility is about changing businesses and business processes, as well as sensing environmental changes and responding appropriately (Overby et al., 2005; Van Oosterhout et al., 2005). Yet another business method, lean thinking (e.g., Womack and Jones, 2003), has been introduced in several industries, including software development (Poppendieck and Poppendieck, 2003, 2007) and in public sector organisations (e.g., in healthcare especially) (Radnor and Walley, 2008). Lean development aims at achieving a continuous and smooth flow of production in pursuance of removing waste in processes and increasing customer value (Womack and Jones, 2003; Petersen and Wohlin, 2010). Charette (2003) argues that lean development means creating a change-tolerant organisation that can survive and succeed in times of uncertainty, change and complexity. Both agile development and lean development concepts have been introduced in the software industry to aid companies in turbulent business environments to achieve shorter lead times (Middleton and Sutton, 2005).

Given that the current business environment of information technology (IT) organisations is very unstable and constantly changing, organisations are increasingly adopting agile and lean development practices. Bellomo et al. (2013) state that both industries and governments have been increasingly adopting agile-based incremental software development practices due to their ability to improve speed. Furthermore, lean development has been proposed as away to achieve substantial cost savings and quality improvements (Radnor and Walley, 2008). Both agile and lean practices have been seen to complement each other. Petersen (2010) compared these two practices and found that:

a both practices share the same goals (i.e., they focus on the customer)

b both practices are defined by similar principles (with the principle of 'seeing the whole' being unique to lean) 
c both practices have unique as well as shared principles

d lean does not define processes while agile defines various processes such as Scrum.

Naylor et al. (1999) have defined the term 'leagility' to describe when principles from both agile and lean development are combined in a supply chain strategy. We here use the term 'leagile software development' to denote software development processes that include both agile and lean principles and practices (e.g., Abrahamsson et al., 2002; Womack and Jones, 2003; Petersen, 2010).

The adoption of leagile practices has encouraged organisations to change the way they execute product and service development and business development. Organisations are affected both by external changes (e.g., economy, competition and political interference) and internal changes (e.g., management systems, organisational culture and employee morale). External changes are caused by the above-mentioned agile and lean developments, which have led in many organisations to continuous and iterative product development. Internal changes are caused, for example, by managers' willingness to continuously improve transparency (i.e., the visibility of information to support decision-making in an organisation). Such developments within organisations have led to business environments with more streamlined process structures and continuous competency development. The organisations strategy process also has begun to align more toward a value-oriented and continuous-based planning. Therefore, strategic and financial plans are not created on an annual basis anymore. Instead, the organisations strategy changes based on customer and market needs, execution and the identification of new opportunities. In order to eliminate disconnection between important activities in the organisation, Fitzgerald and Stol (2014) emphasise that the continuous integration of software development and its operational deployment, as well as the connection between business strategies and software development, should be continuously assessed and improved upon. Furthermore, Olsson et al. (2013) argue that software development companies need to move beyond the concept of agile development toward a situation in which software functionality is continuously deployed and customer feedback is the main driver of innovation. Continuous deployment (CD) is the term used to refer to this phenomenon. Although the concept of deploying software to customers as soon as new code is developed is not new and is based on leagile principles, CD expands upon leagility by moving from cyclic to continuous value delivery. $\mathrm{CD}$ is about developing the ability to deliver the smallest added value to the customer, which requires automating all processes that must be executed to deliver software to customers (Järvinen et al., 2014). New and innovative approaches that support continuous practices throughout organisations are needed, continuous planning being one of them, to remove disconnection between organisation's important activities.

Continuous planning is about developing planning practices continuously, not just once or twice a year (e.g., Hope and Fraser, 2003). Rickards and Ritsert (2012) point out that even though organisations are expected to have continuous planning practices (e.g., quarterly rolling forecasts and budgets),only a minority of enterprises use them. They suggest using continuous planning instruments instead of traditional, static tools in the belief that environmental changes trigger planning instead of the financial year and thus, that plans should be adjusted according to internal and external events (Rickards and Ritsert, 2012). In order to achieve continuous planning, organisations need to be capable of changing their operations and adapting their mind-sets toward continuous planning and transparency throughout entire organisations. 
This article focuses on continuous planning, which is a relatively new and poorly-studied field of research. Hence, the literature on continuous planning is currently inadequate. This research topic is relevant both from the perspective of a leagile organisation, in terms of providing information on methods and techniques for planning and from an agile systems design and evolution perspective, in terms of the creation of content and strategies. The main goal of this article is to identify the current methods and practices of continuous planning in three information and communication technology (ICT) companies. The research questions for this research are as follows:

- How is continuous planning being conducted in agile and lean software development context?

- What are the main benefits and challenges of continuous planning?

This article provides evidence from multiple case studies from which data was collected via interviews, a series of meetings and workshops, as well as through the analysis of company-specific internal memos. The case studies were based on the experiences of three ICT companies: Elektrobit (EB), F-Secure and Tieto. Each of the companies is a large, Finnish-based company with more than 1,000 employees. EB and Tieto operate in the domain of IT products and services, whereas F-Secure operates in the domain of data security. Each of the companies has transformed their organisational practices first in terms of an agile method and then with a lean approach.

In examining continuous planning, this article will focus on its main elements: organisational planning, strategic planning and business planning. Each of these elements is vital and tightly related to one another. Organisational planning defines the organisational level and timeframe of a plan, strategic planning forms the overall plan of an organisation and business planning forms the budgeting frame of a plan. This article will also discuss the implications of continuous planning, including the motivation to implement it and the main benefits and challenges of continuous planning. Companies seeking to develop or improve their continuous planning processes and practices should take all of the components of continuous planning into account to understand how adopting continuous planning can yield significant benefits for an organisation.

This article is structured as follows: in Section 2, continuous planning is defined based on the current literature, including an overview of continuous planning, organisational planning in terms of levels of planning and time frames (i.e., roadmapping), strategic planning and business planning. In Section 3, the research design of this article is presented and the backgrounds of the case companies are described. In Section 4, the research evidence of the empirical studies is given in terms of how continuous planning is conducted in each of the case companies. In Section 5, the research results are discussed, followed by a validation of the study and the limitations of its research results. Finally, Section 6 concludes the paper and directions for future research are given.

\section{Related work}

In this section, we will outline the current knowledge on continuous planning based on the existing literature and research. This literature review was undertaken to define the current state of continuous planning research and to offer a context for the case studies of 
this paper. First, a background on continuous planning is given, followed by the main elements of continuous planning, including organisational planning, strategic planning and business planning. Thereafter, roadmapping is described in greater detail. Finally, the main findings of this section are summarised in relation to a definition of continuous planning.

\subsection{Overview}

Planning can be understood as consisting of two things: actions and forecasts (i.e., expected outcomes).Whereas forecasting can relate to technology or market trends, planning can relate to products, product lines, resources, or an entire company (Van de Weerd et al., 2010). Continuous planning involves implementing planning practices continuously, not just as part of a top-down annual event (e.g., Hope and Fraser, 2003). Planning should be done continuously so that the full scope of development can be presented at any time (Westkamper and von Briel, 2001). Fitzgerald and Stol (2014) define continuous planning as a holistic effort that involves multiple stakeholders from business and software areas. Planning is understood as a dynamic, open-ended process that evolves in response to changes in a business environment and thus involves the tight integration of planning and execution. In terms software development, continuous planning refers to the organisational capacity to conduct planning in rapid parallel cycles (in hours, days, weeks, or months) depending on the level of planning.

Myers (1999) has stated that continuous planning is required in today's organisations and that it will be increasingly important in the future. The continuous operations of organisations have necessitated the ability to produce open-ended plans that develop and evolve in relation to the dynamics of an environment. Furthermore, incremental planning techniques have also been required to respond to changing situations. In response to these requirements, Myers's (1999) developed the continuous planning and execution framework (CPEF), which sought to combine plan-generation and plan-use capabilities to solve complex tasks in unpredictable and dynamic environments. Continuous planning is taken in the CPEF to be driven by the two following notions: first, plans should be understood as dynamic and open-ended which evolve in response to ever-changing environments. Second, users are understood as integral to the overall planning process in terms of providing inputs that will influence the type of plan that is generated, the number of options to consider, failure assessments and plan-repair strategies.

With the adoption of agile and lean development practices, the practice of continuous planning has evolved toward constant planning in small increments and with more people than is typical of traditional software development methods. Shalloway et al. (2009) have presented a continuous planning process related to software releases performed before each iteration and during daily stand-up meetings. Continuous planning at the project level is done in relation to what is known (e.g., looking two to four weeks forward), the plan is for the next iteration and the work that will be for today. Various industrial experiences (e.g., Lehtola et al., 2007, 2009) of companies have shown that they perform open-ended planning with a pre-defined rhythm. However, while planning can be undertaken at regular intervals, the horizon of the future is not fixed. Company planning is often performed looking only one to two releases ahead, with planning for the near future given greater detail than for the remote future, which is only roughly outlined. Open-ended planning is an effective form of market-driven planning that understands 
decisions as involving various trade-offs between now and later (Lehtola et al., 2007, 2009).

It has only been recently realised that planning should be examined from a broader, even more continuous perspective. Continuous planning is not only a project- or team-level activity, but involves higher-level planning as well (e.g., strategy level planning). In the software development context, according to Fitzgerald and Stol (2014), the only forms of continuous planning have emerged from agile development approaches and are related to sprint iterations, or at best, software releases. They conclude that continuous planning is not widespread throughout organisations in the context of software development. Recently, Heikkilä et al. (2013) adopted a three-level planning model, including strategic planning, release planning and operational planning for a large-scale agile software development organisation. Strategic planning involves interaction between business and management and development and is performed over the long-term. Release planning refers to the feature content of the next release and to planning aiming to create content efficiently. Operational planning concerns the implementation of features on day-to-day basis. Heikkila et al. focus on release planning, however, without going into detail on strategic or operational planning. Thus, their understanding of continuous planning lacks a broader perspective.

Several factors of continuous planning can be found in the literature. Koenigsaecker (2009) discusses governance as one of the key issues in a lean organisation's planning process. An organisation's planning process should cycle through each level of leadership returning to the first level of the organisation. Bogsnes (2008) considers organisational planning to be about leadership and creating conditions for good performance to take place, which require an environment of trust and transparency. Accordingly, leaders should work to establish clarity, capability and commitment among their employees. Cosner et al. (2007) emphasise the ability of roadmapping (i.e., a process for documenting the evolution of a company's markets and the product and technology development plans to address those future markets) to link different levels of plans (i.e., portfolio management and finance processes). Roadmaps can be used as guides for skill and competency development as well as for human resources in terms of building competencies that are beneficial to a company's future. In summary, the factors of continuous planning found in the literature include governance, leadership, transparency and competency development.

\subsection{Organisational planning}

The most important aspects of organisational planning are the required planning levels and timeframes (Lehtola et al., 2007). A planning level relates to items that are being planned, whereas a timeframe refers to the time periods of a plan. A company developing and improving its planning practices should define these aspects before initiating aspects of planning. Long-term planning, known as roadmapping, is one solution to bridge the gaps between different levels of planning. According to Cosner et al. (2007) roadmapping should be seen as part of a company's overall business processes and be integrated into its planning cycles. In this section, an overview of organisational planning based on the literature will be discussed in further detail. Roadmapping will be discussed in more detail in Section 2.5.

One of the most important aspects of organisational planning are required planning levels. However, there is no simple answer as to how many levels of planning a company 
should have, as both company size and organisational structure play a role in this decision (Lehtola et al., 2007). Agile at the enterprise level requires examining an organisation's entire value stream, management and delivery team planning levels (Shalloway et al., 2009). Cohn (2006) has presented an agile approach to planning called the 'planning onion' that describes the hierarchical relationships between different facets of planning. The planning onion (shown in Figure 1) consists of the following levels of planning: strategy, portfolio, product, release, iteration and day.

Figure 1 Planning onion

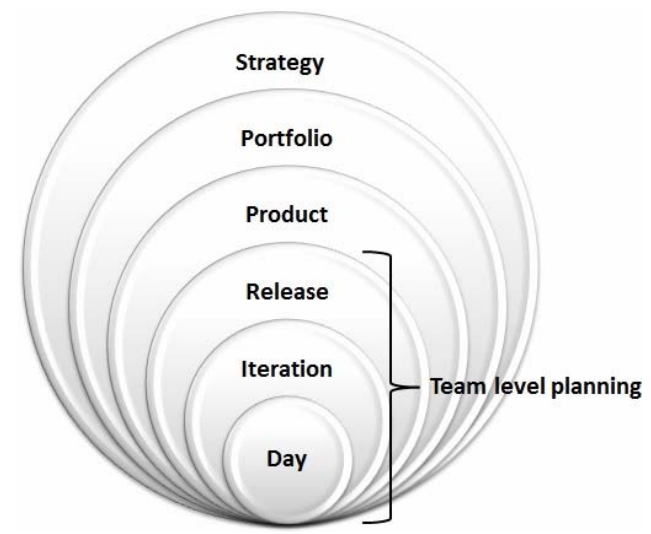

Source: Modified from Cohn (2006)

According to Cohn (2006), planning should not extend beyond a planner's horizon. Instead, it should allow time for a planner to pause, examine a changing horizon and make adjustments with a progressively evolving plan. Agile teams achieve this by planning for three distinct horizons: the release, the iteration and daily planning. Release planning considers user stories or themes in relation to a new release with the goal of determining the scope, schedule and required resources for a project. A release plan should be updated throughout a project so that it will always reflect the current expectations as to what will be included in the release. During iteration planning, which takes place at the start of each product iteration, a product owner identifies the work that a team should address for a new product iteration. Daily planning meetings are meant for organising work and synchronising daily efforts. Cohn (2006) explains that product, portfolio and strategic planning commonly exist outside of the concern of most agile teams. While product planning involves looking further ahead than the immediate release and planning for the evolution of are leased product or system, portfolio planning involves the selection of products that will best implement the vision of a company's strategy. In terms of daily and operational planning, Ruhe (2010) has pointed out that both can become difficult without a proper release plan that is well-aligned with the product and portfolio strategy of a company.

Leffingwell (2011) has presented a framework called agile enterprise big picture, which considers both organisational and process models for agile practices. This framework consists of three levels: the team level, the program level and the portfolio level (Leffingwell, 2007, 2011). According to Leffingwell's framework, from an organisational planning point of view, agile development affects, among others, planning and scheduling in software development and in software project management. 
The team level planning happens in relation to two aspects of product development: iterations and releases. At the team level, agile team members define, build and test user stories in a series of sprints or iterations (i.e., short time-boxed events) to combine larger, system-wide functionality for release of products, features, or architectural components to external users. Many teams have four to five iterations of development with the cadence of each potentially shippable increment coming roughly every 90 days, which creates a quarterly planning rhythm for an entire company. Furthermore, the responsibility for planning is transferred to the teams. At the program level, planning is accomplished by the release planning function. Release planning is done on a regular basis independent of a project's status and release commitments. At the portfolio level, investment themes relate to the strategic planning horizon, with timeframes spanning from 12 months to over 18 months. Investment themes are used to drive the investment priorities of the company. Therefore, investment themes drive the portfolio vision that is expressed in a series of larger, epic-scale initiatives that will be allocated to various releases over time. Epics express the highest level expression of customer or business needs. Prior to release planning, epics are divided into specific features which in turn are converted in more detailed stories for implementation. Epics are planned in timeframes of 6 to 12 months.

\subsection{Strategic planning}

A generic strategy process can be divided into four stages: analysis, development, planning and implementation (Eppler and Platts, 2009). Bryson (2011) defines strategic planning as follows: "deliberative, disciplined approach to producing fundamental decisions and actions that shape and guide what an organisation (or other entity) is, what it does, and why". Strategic planning means accounting for where you are, where you want to be, how to get there and how these are connected (Bryson, 2011). It also includes the development of timelines, resource allocations, responsibilities and deliverables (Eppler and Platts, 2009). Many similarities have been recognised between strategic planning and roadmapping. For instance, the definition of roadmapping is quite similar to that of strategic planning (Kappel, 2001) as one element of a strategic planning process (Cosner et al., 2007).

Strategy processes vary across companies, but at the group level, they are commonly continuous and issue-driven (Bogsnes, 2008). The various components of a given strategy commonly consist of specific routines and work patterns that vary from firm to firm and between different types of firms (Nordqvist and Melin, 2010). Te Brömmelstroet (2013) states that strategic planning phases can vary widely in terms of how they are organised, be they bottom-up or top-down. However, all strategic planning processes can be seen as part of a multilevel group process in which planning actors work together toward a shared outcome. Furthermore, Bogsnes (2008) states that during the strategy process, strategic objectives are often defined in what is known as a strategy map. Strategic themes are then commonly addressed as needed, or bi-annual executive committee strategy sessions will be held. When there is a major change in an organisation's strategic direction, its strategic objectives are often renewed or revised.

From a leagile organisation's perspective, Mavengere (2013) discusses strategic agility, which he deems especially important in a competitive business environment. He states that supply chain participants should have their own strategic plans that relate to an entire supply chain's plan, yet he does not go into detail on how such plans are created (i.e., the planning process in detail). Koenigsaecker (2009) details a lean strategic 
organisational process in which strategic planning is typically done once per year and is intended as a learning experience. In addition, monthly strategy deployment meetings are held to review progress and create opportunities to share knowledge about lessons learned. The existence of monthly strategy-deployment reviews helps to get a company thinking about how to make its work fundamentally better with each passing month.

\subsection{Business planning}

Every business should have clearly defined objectives and parameters within which to operate. The business planning process provides an opportunity to assess the range of skills needed for a business to succeed and to identify potential gaps within this range. Financial planning and the preparation of marketing plans help to determine whether or not objectives are being achieved. Wareham and Majka (2003) claim that continuous financial planning processes are commonly based on goals formulated in strategic plans, such as the establishment of capital structures appropriate to an organisation's current competitive and strategic position. They also point out that continuous financial planning should involve a capital allocation process that forces an organisation to prioritise capital spending decisions in a way that will improve services provided while also protecting long-term financial capacity (Wareham and Majka, 2003). Furthermore, marketing plans provide measurable targets to compare and monitor progress, as well as set achievements on a continuous basis (Butler, 2012).

In relation to business planning, Rickards and Ritsert (2012) have discussed rolling forecasts and budgets. The most important characteristics of rolling plans compared to traditional forecasts and budgets are as follows:

- a constant horizon independent of the financial year

- periodicity (the rule of quarterly preparation)

- planning is more detailed in early periods and less detailed in later periods

- planning focuses mainly on monetary and non-monetary business drivers that influence monetary results (revenues and costs).

According to Rickards and Ritsert (2012), rolling forecasts and plans (relating mainly to budgets) are commonly performed over a time period typically spanning five quarters (or 13 months) to eight quarters (or 24 months). Furthermore, they claim that many enterprises that utilise rolling forecast and budgets use them in combination with a traditional budget plan. This approach determines to use the lower boundary of five quarters (or 13 months), because at latest, at the beginning of the fourth quarter (or twelfth month), forecasts and budget values must completely cover the next financial year. Rolling revisions of plans ensure that, the length of the time period covered is constantly evaluated so that new information is integrated into plans. By doing so, more detailed forecasts and budgets can be made for upcoming quarters both near and far in the future.

Hope and Fraser (2003) have presented the 'beyond budgeting management model', in which they define budgeting in a much broader way than is commonly understood. One of the highlights of this model is that it understands budgeting, planning and improvement as a continuous and customised process, not just as parts of an annual event (Hope and Fraser, 2003). According to Bogsnes (2008), similar to the rolling forecasts 
and plans presented by Rickards and Ritser (2012), five-quarter rolling forecasts have become a standard in 'beyond budgeting' implementations. However, Bogsnes (2008) clarifies that even though a five-quarter rolling horizon is better than stopping planning at the year-end, planning is still done in a fixed period. Hence, a more dynamic planning process that is more event-based than calendar-driven with no fixed update frequency and with no fixed time horizons should be developed (Bogsnes, 2008).

From an agile organisation perspective, Leffingwell (2011) has pointed out that a set of strategic investment themes drive the organisations vision of all products, systems and services and the responsibility of investment decisions generally lies with a portfolio management team. In most enterprises, investment decisions occur at the business unit-level based on an annual or bi-annual budgeting process. During the budgeting process, the amount of funds available for each business unit or product to invest in development is determined (Leffingwell, 2011). It has been shown (Cosner et al., 2007) that budgeting process should be aligned with the key milestones and events of an organisation's roadmap. More specifically, a budgeting process should include the following three elements; first, research and development (R\&D) categories for development resources in each major capability of a roadmap; second, categories of resources for operations that support different capabilities; and third, life-cycle funding plans that forecast necessary 'ramp-ups' as well as simultaneous 'ramp-downs' in operational funding related to different types of capabilities shown on a roadmap.

\subsection{Roadmapping}

In general, a roadmap is a layout of existing routes or paths that is used to decide among different directions toward a desired destination (Kostoff and Schaller, 2001). Roadmaps are forecasts of what is possible or likely to happen and plans that express a course of action (Kappel, 2001). Roadmaps are also intended to be living documents, to be reviewed and updated over time in order to remain useful (Albright, 2003). Roadmapping describes the process of creating and revising roadmaps (Kostoff and Schaller, 2001). Roadmaps can be expressed in various forms, types and with different taxonomies (Kameoka et al., 2003) and should answer a common set of 'why-what-how-when' questions that generally relate to markets, products and technologies (Phaal et al., 2005). A more detailed summary of existing roadmapping processes along with their main areas of focus (i.e., goals and main phases) is presented in Suomalainen et al. (2011).

A roadmap's architecture consists of two dimensions: timeframes and layers and sub-layers (Phaal and Muller, 2009), with each layer of information providing input for the next level (Cosner et al., 2007). Cosner et al. (2007) describe enterprise roadmap development as being divided into the following layers: strategic roadmap, market roadmap, product roadmap, technology roadmaps and enterprise roadmap. Figure 2 describes the interrelationships between these roadmaps. A strategic roadmap deals with the long-term objectives of senior management. A market roadmap presents known and predicted customer needs along with, for example, competitive strategies, the regulatory environment, complementary product evolution, substitute products and innovations. In a roadmap strategic goals and market targets are defined as milestones or in terms of target dates for certain events. Product roadmaps are for documenting performance and feature evolution, as well as presenting new-to-the-company products and new-to-the-world products. Technology roadmaps include expected R\&D products, their availability dates, driving factors for $\mathrm{R} \& \mathrm{D}$ and related information. An enterprise roadmap combines these 
different types of roadmaps across an entire enterprise. While each roadmap presents existing plans, the enterprise roadmap may suggest alternate, unfunded plans that could be considered.

Figure 2 Enterprise roadmap development

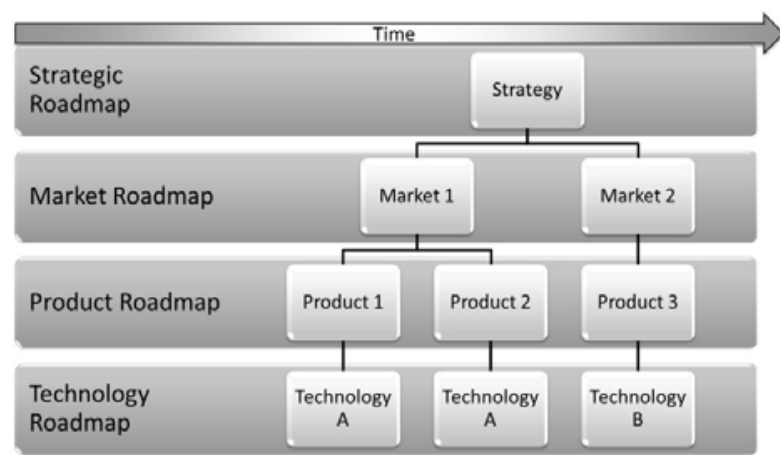

Source: Modified from Cosner et al. (2007)

Five broad time periods have been recommended for inclusion in roadmaps: the past (and current situation), short-term, medium-term, long-term and vision (Phaal and Muller, 2009). The past-timeframe helps to understand key influences and events that have led to the current situation, as well as highlights learning points that will influence the success of future plans. A short-term consideration typically looks at a one-year period and is the most important output of a roadmap, including tangible plans and committed actions. This timeframe can be understood as a budget horizon for resources to be committed so that actions can be fulfilled. Medium-term periods are typically around three years and are linked to strategic planning projections that highlight the broader direction and options that influence short-term directions and plans. A long-term timeframe is typically a ten-year timeframe that represents a bridge between the medium-term strategy and the vision of an organisation. This time frame includes the articulation of key uncertainties and scenarios, as well as the exploration of long-term shifts in technology, business and market environments. In addition, it allows an organisation to capture and assess longer-term issues that may affect current decisions and plans. Lastly, a company's vision relates to knowing where it is going and setting long-term goals.

\subsection{Summary}

In conclusion, continuous planning involves the continuous implementation of planning practices in rapid, parallel cycles instead of predefined and regular planning occasions. Continuous planning reacts to environmental changes, with internal and external changes triggering planning in addition to a predefined planning rhythm. The timeframe of a plan can vary from hours to months depending on the level of planning. The main elements of continuous planning are as follows: defining the organisational level and timeframes of a plan (i.e., roadmapping), strategic planning to form the overall plan of an organisation and business planning to establish a budgeting frame for a plan.

Examining the literature on the subject, continuous planning is a relatively new and insufficiently studied field of research. The current literature focuses mainly on certain specific levels of planning in an organisation exclusively and lacks a broader perspective 
of continuous planning. In relation to what is stated in the current literature, the cases of this study were found not to be applying continuous planning throughout their entire organisations, instead applying it only at certain levels of planning (e.g., release planning, especially in the leagile context). In addition, since strategic and business planning is of less concern to most agile teams, these are not described in detail either in the literature. Literature pertaining to continuous strategic or business planning in from a leagile perspective is particularly lacking at present. In addition, based on the literature review of this study, there is very little empirical research of continuous planning that describes how continuous planning is conducted at different levels of planning. Therefore, this study argues that continuous planning requires greater research with a broader perspective than it has previously been given. The intention of this research is to increase the current empirical evidence on continuous planning and roadmapping both for industries and the field of science to develop improved planning practices.

\section{Research design}

In this section, the research design of this article is described. The research goals, methods and process will first be introduced, followed by a description of the case companies and data collection methods.

\subsection{Research methods and process}

The goal of this research was to identify current methods and practices of continuous planning. The research aimed to define what continuous planning means and to determine how industry players perceive it in order to increase the current empirical evidence on continuous planning for players in the fields of industry and science to further research. The research questions of this study are as follows:

- How is continuous planning being conducted in agile and lean software development context?

- What are the main benefits and challenges of continuous planning?

This research includes a multi-case study (Yin, 1994). A case study research approach was decided upon because the literature on the continuous planning is not yet well-formulated and statements on practical experiences in the field of research were difficult to find. Järvinen (2001) emphasises the ability of case studies to examine very complicated circumstances and, in this way, to gather information for the creation of new knowledge. In addition, the case study methodology has been stated to be well-suited for software engineering research, as it involves the study of contemporary phenomena in its natural context (Runeson and Höst, 2009). Furthermore, case studies are especially appropriate when context is expected to play a role in the phenomena of focus (e.g., if the stresses of a given project affect developers' behaviours), or when effects are expected to be wide-ranging or to take a long time (e.g., weeks, months, or years) to appear (Easterbrook et al., 2008), the latter of which was the case in this research.

The research was processed as follows. First, the current state of continuous planning was discerned for each case. Second, empirical research was carried out in which qualitative data was collected through semi-structured interviews (e.g., Järvinen, 2001), a 
series of meetings (with case company A) and workshops (in case company C), as well as the analysis of company-specific internal memos in cases A and B (described in more detail in Section 3.2). As described, for example, by Yin (1994), such data collection methods align with the selected case study research method quite well. The interviews were conducted in all the three case companies. The interviews were analysed using the generic process of data analysis presented by Creswell (2003). After each interview, a digital recording was transcribed and thereafter, all data was read through in order to obtain a general sense of the data. A coding process was used to categorise the data and label the categories. The purpose of the coding process was also to generate descriptions for the categories to generate a small number of themes that represented the major findings of the qualitative data. These descriptions and themes were then presented in qualitative narratives in case descriptions (presented in Section 4). The case descriptions were validated by the interviewees by their reading them through and making corrections to them if needed. Finally, based on the empirical research, the current status of continuous planning at each case company was decided upon.

\subsection{Case companies}

The research included three global ICT companies: EB, Tieto and F-Secure. One of the main reasons for selecting these case companies was because they had transformed their organisational practices to use an agile method (more precisely, the Scrum method (e.g., Abrahamsson et al., 2002) and then complemented this later on with a lean approach (e.g., Middleton et al., 2005). The case companies and the study's respective data collection methods are presented in Table 1.

Table 1 Case companies

\begin{tabular}{ccccccc}
\hline Case id & Company & $\begin{array}{c}\text { Role of the } \\
\text { interviewee }\end{array}$ & $\begin{array}{c}\text { Number of } \\
\text { employees }\end{array}$ & Industry & $\begin{array}{c}\text { Start of agile/lean } \\
\text { transformation }\end{array}$ & $\begin{array}{c}\text { Data collection } \\
\text { method }\end{array}$ \\
\hline Case A & EB & $\begin{array}{c}\text { Head of } \\
\text { quality and } \\
\text { environment }\end{array}$ & 1,800 & $\begin{array}{c}\text { IT, } \\
\text { products } \\
\text { and } \\
\text { services }\end{array}$ & 2007 & $\begin{array}{l}\text { Series of meetings } \\
\text { and an interview } \\
\text { with the case } \\
\text { company } \\
\text { representative; } \\
\text { analysing company } \\
\text { internal data }\end{array}$ \\
Case B & F-Secure & $\begin{array}{c}\text { Project } \\
\text { manager }\end{array}$ & 1,000 & $\begin{array}{c}\text { Data } \\
\text { security }\end{array}$ & 2005 & $\begin{array}{l}\text { An interview and } \\
\text { analysing company } \\
\text { internal data }\end{array}$ \\
Case C & Tieto & Scrum team \\
roles & 18,000 & IT & 2006 & $\begin{array}{l}\text { Six interviews, nine } \\
\text { workshops and three } \\
\text { follow-up meetings } \\
\text { between workshops }\end{array}$ \\
\hline
\end{tabular}

\subsubsection{Case $A(E B)$}

Elekrobit (EB) is a global company with roughly 1,800 employees that provides cutting-edge technological solutions to the automotive and wireless industries. The company operates in more than ten countries and has 12 subsidiaries. The company provides development services for wireless products, including mobile phones and 
navigation systems, as well as sells radio channel emulators for testing wireless products. EB also offers software for designing and implementing infotainment systems for the automotive market. The EB research data was collected during 2011-2012 via a series of meetings and one interview. In 2011, eight meetings were held to exchange information on continuous planning in which three persons were involved: two researchers from VTT and one representative of the case company. During the meetings, the vital elements of continuous planning were discussed and drafts of the company's continuous planning framework were drawn up. Then, in 2012, a semi-structured interview was held to clarify how continuous planning is conducted at EB, as well as how information is transferred between different levels of the organisation.

\subsubsection{Case B (F-Secure)}

F-Secure is an anti-virus, computer security and computer software company with approximately 1,000 employees in 20 offices around the world. The company provides software products for digital content protection, such as internet security, antivirus, mobile security and anti-theft software, as well as a range of free online tools as a service through operators. The company has partnerships with more than 200 operators and it operates 22 wholly-owned subsidiaries. The research data on F-Secure case was collected in 2011 during an interview and by analysing the company's internal data. The interview was organised as a semi-structured interview that sought to process the vital themes of the research. The interview lasted one hour and 40 minutes and involved one interviewee and two interviewers. Thereafter, the interview was transcribed and analysed. After the interview, internal memos pertaining to continuous planning at F-Secure were analysed. This data included information related to continuous planning practices that were discussed during the interview, yet this information was nonetheless considered vital in terms of clarifying and verifying the practices and processes of the company related to continuous planning.

\subsubsection{Case C (Tieto)}

Tieto is an IT service company that provides IT, R\&D and consulting services. With approximately 18,000 experts, it is among the leading IT service companies in Northern Europe and is a global leader in certain areas of the field. In this case, the study focused on the sustainability intelligence R\&D team (SI team) at Tieto. The research data of the Tieto case was collected mainly in 2010-2012. During 2010-2011, six one-day workshops and three follow-up meetings that used the value-stream mapping (Abdulmalek and Rajgopal, 2007) method were conducted. In the workshops, the team members chose the most critical processes from their perspective, described the current state, as well as identified bottle-necks and improvement actions for their chosen processes. Based on their identified improvements, they then drew a future-state map of the selected processes. In the follow-up meetings, which were conducted between the value-stream mapping workshops, the selected processes and practices were modified by the team when needed. Additionally, six team members were interviewed in the spring of 2011. These interviews focused on exploring what the development methods of the team were and how the team developed the new cloud service. The interviews also revealed underlying needs for continuous planning. Finally, in the beginning of 2012, three 
two-hour workshops were organised in which the team members improved the processes to align with the idea of continuous planning.

\section{Research results}

In this section, the research evidence from the empirical study is presented and the continuous planning processes of each case company are introduced. The research results are presented in terms of Cohn's planning onion framework (presented in Section 2.2.1). By different line styles, Figure 3 illustrates the level of continuous planning predominantly used by each of the case companies.

Figure 3 Continuous planning at the case companies

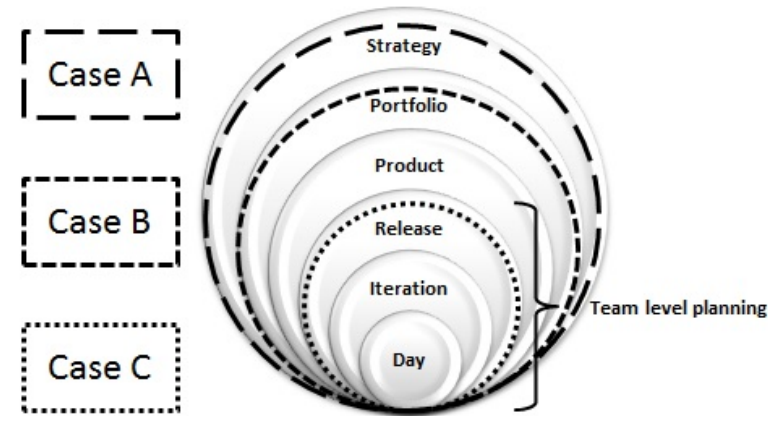

As can be seen in Figure 3, the continuous planning process in case A begins at the strategic layer. Case $\mathrm{B}$ focuses on project and team-level planning in beginning at the portfolio layer and case $\mathrm{C}$ focuses on team-level planning beginning at the release layer. Case C's team, however, only verbally communicates at the portfolio and strategy level. The team layer represents the core of the planning onion, with agile teams performing planning at the release, iteration and day layers. The product, portfolio and strategy layers are commonly of lesser concern, because they commonly exist outside the concern of most agile team according to Cohn (2006).

\subsection{Continuous strategic planning}

In case $\mathrm{A}$, the chief executive officer (CEO) of the company is responsible for the entire company's strategy process and the heads of the company's business segments are responsible for strategy in their respective fields. There were two facilitators at the case company, one for the automotive segment and one for the wireless segment. The motivation for continuous planning at the company stems from the fact that plans cannot be fixed for one year ahead anymore. Instead, plans must be able to change continuously, as the business environment is constantly changing. Thus, the evolution of planning toward continuously iterated and updated product and service planning and roadmaps was needed. Furthermore, even though a strategy exists at all times within the company, it is now iteratively and continuously updated based on market and customer demands. Past financial crises have also caused the company to realise the importance of continuously planning ahead both from an operational and financial perspective. 
The need for continuous planning practises also relates to transparency in order to share information. It had been realised by the interviewee that the transparency and continuous planning of all the activities throughout the organisation were needed. The company needs continuous visibility of its development and operations in order to share and provide information with all employees. On the one hand, operational transparency is related to increasing the visibility of the performed work, plan and executed actions in relation to the fulfilment of one set of defined criteria. On the other hand, development transparency is related to identifying the potential technological and cultural barriers to implementing increased transparency and improving learning in connection to needs that arise due to increased transparency. Also, knowledge sharing had become increasingly important inside the company. The representative for case A defined in one of the meetings that "both push (e.g., trainings) and pull type (e.g., publishing information via wikis and articles) of knowledge sharing is needed". Furthermore, the representative clarified that, beyond this visibility, continuous competency planning and development are needed. Employees' competencies had to be able to adapt constantly and change through continuous analysis, development activities and evaluations as to the successfulness of actions.

The continuous planning process was launched in November 2010 at case A, including financial and strategy planning that adopted many of the 'beyond budgeting' model's principles. At first, the strategic actions were walked through, defined and reviewed on a quarterly basis. Next, the intention of the company was to have a continuous strategy that would be continuously connected to the goals established in bi-weekly reviews with different teams. Based on the interview data, two main levels of continuous planning were recognised: financial planning and strategic planning. Each of these levels involves approximately one fourth of the personnel in the business segments in the irrespective planning processes.

The financial planning means that the financial framework is conducted only once a year. Thereafter, the planning is continuous. The case company's change toward continuous financial planning began in 2012 and there has not been bi-annual budgeting since then. Continuous financial planning means that there is a continuously available financial forecast. For example, currently the company has a rolling forecast for budgeting until the end of the next year. The framework is created at the end of each year (in November), which includes a budget overview of the rest of the following year. The idea of the financial planning is constant in that actual expenses are continuously considered and compared to budgets. Thus, financial actions involve each of the budget items in the short-term and initiatives for the long-term. For example, planning training, which constitute expenses (e.g., common and travel), are budgeted and forecasted.

Strategic reviews are done quarterly and are visible at different levels of the company (e.g., business, market, technology, processes, roadmaps, operational modes, partnerships and action plans). These different levels also have a financial perspective. Strategic planning and financial planning are closely tied together because they both are visible at different levels of the company.

Currently, the strategy process is constantly rolling, which means that the strategy is continuously planned. The main phases of the strategy process are as follows:

1 strategy review

2 strategy development and acceptance 
3 strategy communication and execution.

The main actions of the business segment's strategy process are as follows:

1 a strategy health check

2 vision and strategy guidance and direction, which includes strategy and roadmap planning, as well as long-range financial planning for the next three years, plus the current year

3 communication of the strategy and execution of the action of the strategy.

The timeframe for the long-term strategy, roadmap and financial planning is the approaching three years plus the current year. The strategic or financial framework for the next year is established prior to the end of the year in a short planning cycle. Thereafter, the framework along with the plans is reviewed quarterly and monthly. The continuous strategy process, along with the phases and their actions, are shown in Figure 4, which was drawn based on both the data from the interview and the company-specific memos.

Figure 4 Continuous strategic planning (case A) (see online version for colours)

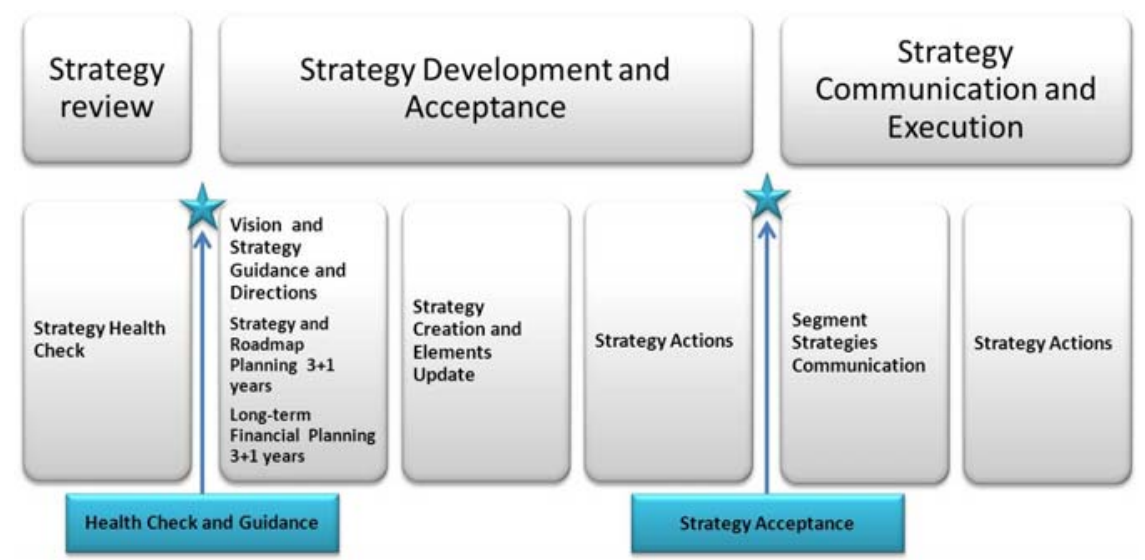

A strategy health check is done annually at the end of the year from December to January, during which period of time the current status of the strategy is reviewed. Needs for major strategy updates (e.g., establishing a new business area) are addressed in January. At the end of January, strategic work is considered in relation to initiated strategy elements that need to be updated and plans are made regarding how to proceed with the strategy, especially in terms of changed elements.

The vision and strategy guidance and directions are planned for a timeframe of the forthcoming three years plus the current year. The strategy, roadmap planning and financial planning are done from a three-years plus one-year perspective. Thus, the company's strategy is always understood at all times as a whole, yet its various elements can be changed at any time. In the beginning of the year, changes to the strategy are reviewed in a phase known as the strategy creation and elements update. New strategy element updates are approved in April (by the segment board), followed by board strategy acceptance. The updated strategy is communicated to the employees in May. The 
strategy communication is the only action that is performed as an exact time yearly. Otherwise, planning was considered continuous.

To summarise, the strategy frame is reviewed annually and roadmaps are updated quarterly. Plans are reviewed quarterly and at the same time strategy-related outcomes are reviewed. Management reviews the strategy goals quarterly or when needed. In the quarterly strategy review, the following aspects are checked: the current status, the latest updates to strategy and progression of the strategy deployment. After the strategy review, the review results are re-reviewed by the company's business areas. Then, as the interviewee put it, "it is explained how we have progressed with the goals, where we have lagged behind, and what we have unfinished".

There are two perspectives to the strategy. First, the strategy divides into several roadmaps that are made public and available as online information. Therefore, the strategy is visible to all within the organisation. The business roadmap defines, for example, what new information management services are planned to be released and in which quarter and what their status is. These roadmaps are constantly updated. Second, all the issues and goals related to the strategy are made visible via a tool called Jira ${ }^{\mathrm{TM}}$ (a commercial software product). Therefore, outcomes can be reviewed in real-time.

\subsection{Continuous portfolio and product planning}

In the case $\mathrm{B}$, the interviewee was involved in a global project operating in three sites. The project was seeking to come up with an overall solution that involved background systems and several clients in close cooperation. The interviewee's role was project manager. The need for continuous planning was recognised in the company given the fact that its business and R\&D units did not work together as well as expected and tensions between the primes could be pinpointed. Furthermore, it had been R\&D's long-term wish to achieve shorter planning cycles. Therefore, in the beginning of 2010, Dean Leffingwell (author of the agile enterprise big picture, presented in Section 2.1) was invited to coach the company's planning.

Based on the data from the interview and the company's internal memos, the following levels of planning could be defined as existing at case $\mathrm{B}$ : portfolio, project (i.e., features) and team (i.e., stories). For smaller projects, only the portfolio and project levels exist. Projects are managed by handling features and teams are managed through feature stories. The team is comprised of a two-levelled backlog: a feature level and a story level. The higher level of the two, the feature level, is defined during planning and involves features being split into stories for implementation in teams. Continuous planning in case B means planning in terms of three-month intervals. However, the company does extend its foresight forwards up to six months in terms of some kind of deliverable and scope.

Continuous planning at the project level is conducted as follows. The most important issue for the team is the work amount, which can range from one to four sprints (i.e., time-boxed effort). Another important issue is customer value, which means that a customer can understand what the team is doing. A project plan is one of the team's outputs, which is co-created so that everyone can see the same artefact and suggest improvements. The project plan includes a scope, resources and schedule. The schedule for the project includes a scope and resources that are each separately planned. The interviewee explained as follows: "So, first, we make estimates, then we make allocations to resources, and finally, we have a plan. That is, all the important parts of the project: 
scope, schedule, and resources". The main activity of continuous project planning is balancing these three elements, which also serves to establish the priority of the items in the scope. The main working method of the team is 'war-room workshopping', which enables proper communication and less confusion, improves team spirit and enables visual planning. The main phases of continuous project planning include scoping, planning and kick-off preparation and sharing, all of which are illustrated in Figure 5.

Figure 5 Continuous project planning (case B) (see online version for colours)

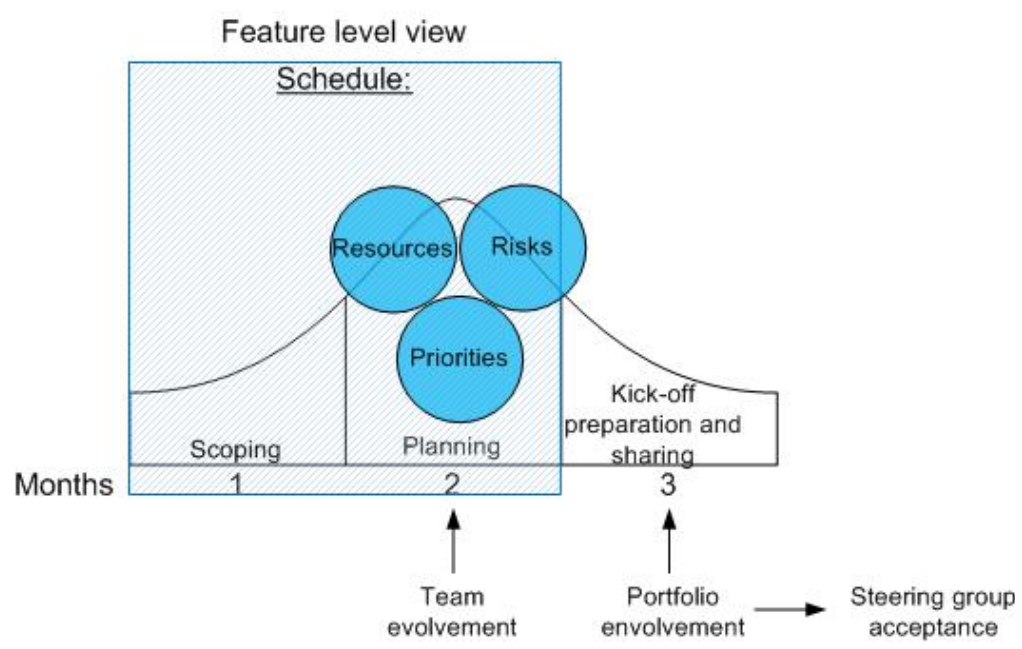

The phases of continuous project planning (Figure 5) areas follows:

1 In scoping, the features are described and listed and then available teams are identified. The next step involves the estimation of the effort required for specific work items, where the team estimates how many sprints are required for each item.

2 In planning, the actual feature level is created. The team discusses the features, organises them on the wall of the workshopping war-room, complements their descriptions and then prioritises them. The left side of the wall shows the most important features and the right side the less important features. The priorities are also divided according to required competencies and the project manager then plans the required resources for the project. The resourcing is then negotiated in relation to the portfolio and human resource management and the planning office is responsible for ensuring all of the teams' allocations to projects. Teams are selected based on a given project's business cases. The planning also considers constraints related to resourcing and more explicitly, associated risks and priorities. Risks are identified on separate areas of the war-room walls. Anyone in the team is allowed to post risks as well as to resolve them. Risks are discussed continuously, with the main idea being to continuously change the project plan to eliminate risks. In sum, in order to eliminate risks the team either includes mitigation as part of the scope of a project or changes its approach so that risk probability is reduced. Thus, the interviewee pointed out that risks feed planning actions and changes to the plan. The team is openly invited (during a specified timeslot) to see the content and resources of the next project, which calls for team evolvement. 
3 In kick-off preparation and sharing, the project plan, including features and risks, is presented by a team member to the portfolio owners (i.e., project business directors and vice presidents), which calls for portfolio evolvement. The team then asks for approval or requests changes from the steering group. If changes to project plan are needed, another meeting is held after one or two weeks, or otherwise, the team progresses with the plan. The project portfolio steering group includes all of the required persons, including those at the executive team level. Finally, once the plan is approved by all involved, the plan can be shared with other teams.

\subsection{Continuous team-level planning}

In case $\mathrm{B}$, the team performs continuous feature planning on a weekly basis to keep its priorities and visibility of the team's status up to date. The continuous planning of features is performed in the form of a feature priority queue, which involves the creation of a row (or queue) of features in order of priority (with the most important features on the left) and the address of these features, primarily to acquire an understanding of a feature's size. This planning is then completed with resourcing capacity so that each feature is matched in terms of size from left to right, starting with the highest priority. Size is determined by 'team sprints' (i.e., how many full sprints by a single team will be required to complete a feature). This team level planning focuses on the essence of planning prioritising and estimating. When an understanding of this is achieved, planning can be conducted continuously and iteratively. As features are completed on the left, they are removed from the queue. New items are entered in a specific position into the priority queue according to the priority they are assigned. This can be planned and re-planned at any time to any degree. Continuous feature planning does not mean that you need to change everything all the time. If a change is needed, a set of features may be fixed. Simply by monitoring progress and recognising that work remaining in the queue matches with the capacity available constitutes continuous planning. The team level continuous planning of case B is presented in Figure 6.

Figure 6 Continuous team-level planning (case B) (see online version for colours)

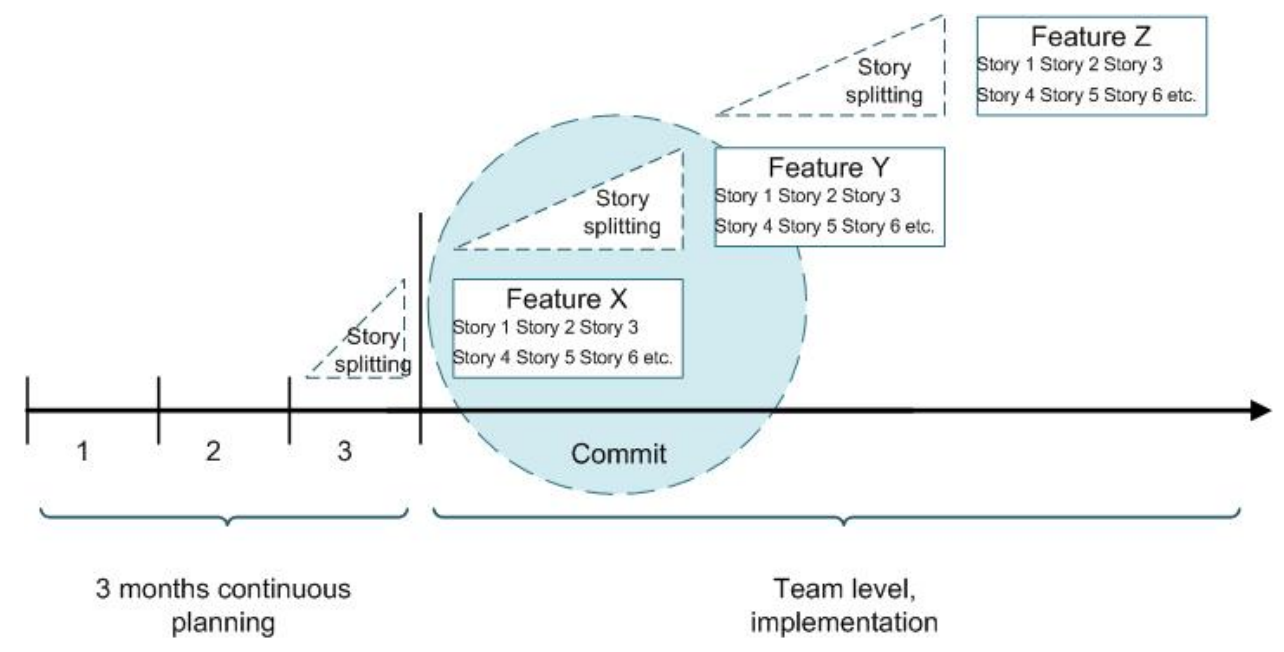


In case $\mathrm{C}$, continuous planning was done at the team level. The team used an agile method (Scrum) and later adopted lean principles. After adopting these leagile practices, the team recognised that the time-boxed and static backlog for sprints was not working optimally. When it was realised that urgent tasks were continuously being presented to the team, this forced it to consider root causes for this and what to do in order to control its work. As a consequence, the team headed toward implementing continuous planning; in parallel with their development activities, the team members also contributed to business planning and strategic planning by introducing new and innovative services to the company's portfolio. The team level planning in case $\mathrm{C}$ is illustrated in Figure 7.

Figure 7 Continuous team-level planning (case C) (see online version for colours)

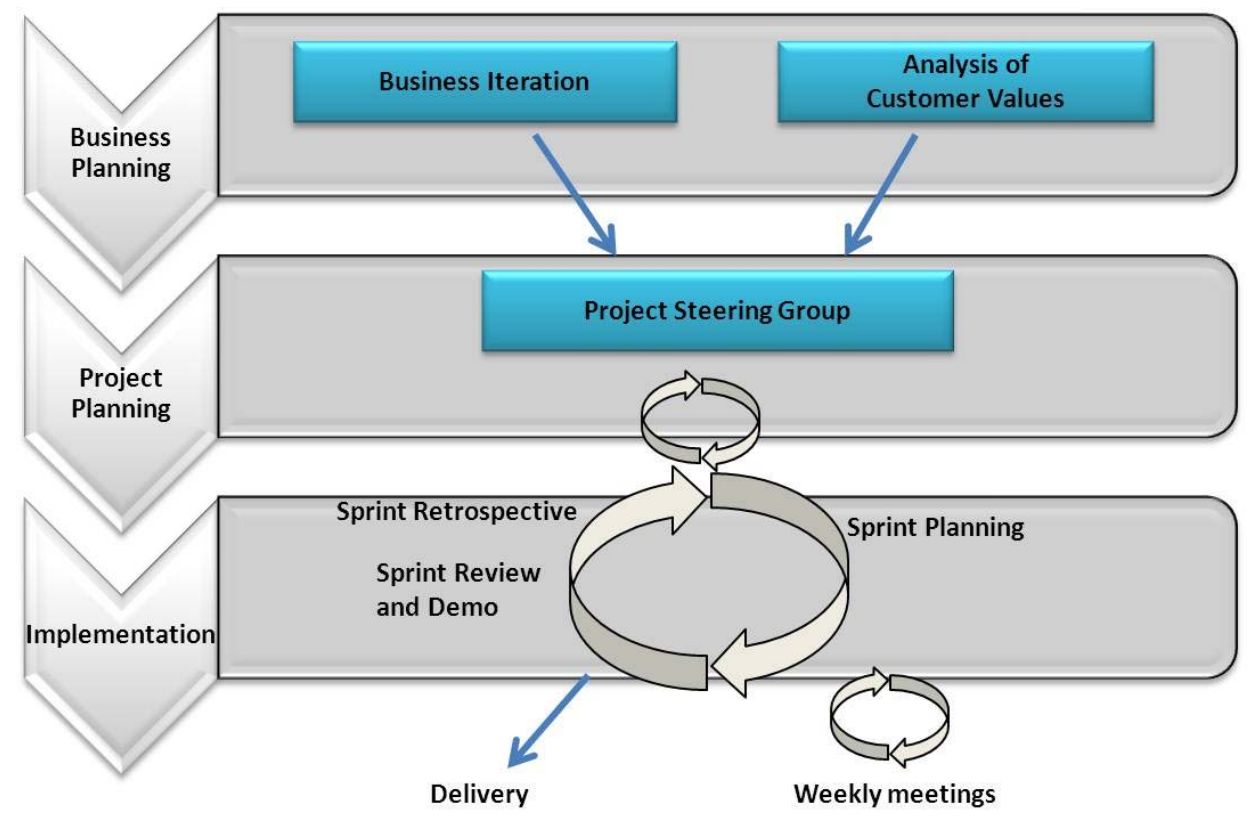

The continuous planning approach in case $\mathrm{C}$ was comprised of the following main activities: business iteration, consumer value analysis, the project's management and planning by a project steering group and implementation. Additionally, some dedicated team members actively participated in business iteration and consumer value analysis, which helped the team to keep up-to-date in terms of service development. While, the team were informed of new requirements in terms of businesses' and consumers' values and preferences, they could merge the team's new ideas into business plans. Most team members also participated in the project steering group meetings.

Business iteration activities involve a series of sprints (i.e., it considers a timeframe that is long enough to enable the production of a release plan that is useful to a business). Business iterations aim at fulfilling business goals and involve results being reviewed and adapted to a larger, business-oriented plan. Consumer value analysis contains three phases: 
1 The survey of consumer values and preferences in a given business context. The intended output of this phase is to create persona dimensions (i.e., personas) and customer profiles. Additionally, descriptions of the main consumer profiles/personas can be used as criteria for tailoring value proposition, fine-tuning marketing messages and improving user experiences.

2 Design implications (i.e., design for end users), which aims at understanding what personas and market segmentation (based on values) mean for a company's design processes, marketing messages and experience creation.

3 Mapping product-related customer value (i.e., design with end users), which aims to understand end users' desired, expected and received value related to a service under development.

A project steering group is a governing body of a project that meets once during each quarter of the year. The group reviews and accepts/rejects the products of business iterations and consumer value analysis. Participants in the group include a product owner, a user-experience specialist, a solution manager, a technical manager, a agile/lean mentor, a consumer value analysis team and a Scrum master. The project steering group organises its activities in order of greatest effectiveness for the project. The group performs problem-solving by informing upper levels in a company of possible problems if the group itself cannot solve them itself. Lastly, implementation work is conducted in two-week sprints following general Scrum practices, such as sprint planning, daily meetings, sprint reviews and demos, sprint retrospectives and continuous integration.

\subsection{Benefits and challenges of continuous planning}

With regard to case A, from a financial perspective, the main benefits of continuous planning were that financial estimates will become more accurate. From a strategic perspective, the interviewee highlighted "we are able to show to the staff current stages of the status, for example, what we have done and where we want to be now, at the mid-term, and in the long-term". Since case A's strategy became reviewed, followed-up, communicated and published quarterly, it has led to increased trust in management, as well as to improved competitiveness and decreased fixed costs. Alternatively, in case B, in terms of R\&D project management, a key benefit of continuous planning has been that it has decreased work-in-progress as well as improved quality levels. The team has learned how to write features because project performance times are now much clearer than they were before. Feature level planning has also become more reliable given the features have not been much modified during the implementation of the product. Second, from a product management perspective, continuous planning has enabled a better level of communication and brought many more people into the planning process. Third, from a portfolio level perspective, a key benefit has been that the people in charge at the portfolio level are now able to come to the war-room and actually see what their team is currently doing because the team progress is presented in the war-rooms wall. This visual wall also makes it much easier to explain why e.g., features and sprints have been done a certain way instead of trying to explain them using a backlog on an Excel spreadsheet in which context, including risks and resources and other additional information, is lost. Furthermore, according to the interviewee, it is quite easy to put additional information on the war-rooms visual wall. 
In case $\mathrm{A}$, the main challenges of continuous planning relate to people (e.g., their willingness to be engaged and involved) and to transparency (e.g., how to make goals visible and place them in a continuous setting). Some people may view continuous planning as leading to a loss of authority among employees. However, it is less about authority or control and more about transparency of information. The general attitude toward continuous planning needs to be embraced throughout an organisation. The main expectations of continuous planning are related to transforming goals into a mode of continuous planning. In case B, the interviewee named several challenges related to continuous planning. For example, one challenge was how to fulfil long-term issues. When long-term goals are taken into account by the management, they should be quickly optimised into short-term business productivity by the team. Due to this, the interviewee posed the following question: "are we taking the longer term architecture and business strategies enough into account?" It was pointed out that continuous planning does not remove the need for long-term planning when the interviewee stated the following: "We need all the time to think of our resourcing needs and our competency needs and location strategy, technology strategy, and all those are of course going on in the background". The portfolio level, for example, was not clearly visible to the team. Only once every three months does someone specify what kinds of projects are about to begin and there were not any tools being used for presenting portfolio-level plans. One of the main obstacles of continuous planning was that many parts of the firm would rather work with long-term plans than three-month plans. For example, the business areas in the case company B wanted a view from six months to one year, but in order to conduct continuous planning, the team needed to state that they could only promise a three-month view, with the long-term view representing only a rough outlook. It was noted that a short-term planning cycle requires a significant mental shift for many actors, especially for those outside the field of R\&D. It was pointed out that a team needs to be aware of incremental development practices in general and their capability to do work must be visible at all times to the rest of the company.

\section{Discussion}

In this section, the research results are discussed and compared with the existing literature. First, the empirical findings from the organisational, strategic and business planning are presented. Second, roadmapping from the perspectives of the case companies will be discussed. Finally, the implications of continuous planning are presented along with the validations and limitations of the research.

\subsection{Organisational, strategic and business planning}

Continuous planning is comprised of organisational, strategic and business planning. As pointed out in literature (Lehtola et al., 2007), the most important aspects of organisational planning are established levels of planning and timeframes and the number and different levels of planning within companies will vary according to size and organisational structure. Evidence of these points was found out in this research. In comparing the three case companies of this study, it can be concluded that they each are relatively different: continuous planning was considered at different organisational levels in each of the cases, which played a role in the differing timeframes of each case's plan. 
Continuous planning was not applied throughout any entire organisation, but was rather focused at a specific level of planning. In case A, two main levels of continuous planning were recognised: strategic planning and financial planning. In case $\mathrm{B}$, three levels of organisational planning were defined: portfolio, project (i.e., features) and team (i.e., stories). However, smaller projects focused only at the portfolio and project levels. The continuous planning process was mainly described as existing at the project and team levels. In case $\mathrm{C}$, continuous planning was mainly at the team level. However, team members contributed to business and strategic planning when introducing new and innovative services to the company's portfolio. In both cases $\mathrm{B}$ and $\mathrm{C}$, continuous planning was conducted by team members, whereas in case $\mathrm{A}$ it was more of a management effort.

Both the literature and the empirical findings of this study find strategic and financial planning to be closely related. According to the literature, a continuous financial planning process is based on goals formulated in a strategic plan (Wareham and Majka, 2003). According to the case studies of this paper, strategic planning is visible throughout an entire organisation, as each of the different levels of plans (e.g., business, market and technology) have a financial perspective on the plans. In case A, long-term strategic and financial planning (as well as roadmapping) were done for a projected three-year timeframe that included the current year. The strategic and financial frame for the following year was developed prior to the turn of the year and thereafter was reviewed on a monthly and quarterly basis. Wareham and Majka (2003) have stated that companies understand financial planning as a capital allocation process in which actual expenses are considered and compared to budgets, where actions are involved in each budget item in the short-term and as initiatives in the long-term.

In order to achieve continuous planning, the case company A adapted many of the 'beyond budgeting' (Hope and Fraser, 2003) principles. They realised that budgeting, planning and improvement had to be recognised as a continuous process, not just an annual event. Financial planning had to be seen in broader context, as suggested by Hope and Fraser (2003), as part of a performance management process. In fact, in this case, financial planning also had to involve continuous roll-over periods rather than biannual assessments. The financial framework of this case was assessed only once a year, yet thereafter its planning was continuous. The continuous financial planning process in case A became similar to the budgeting and financial planning process presented by Rickards and Ritsert (2012).

In case $\mathrm{A}$, the company also changed its strategic actions toward continuous planning in terms of planning and reviewing strategies on monthly or quarterly basis. According to Koenigsaecker's (2009), planning should be done once per year and strategy deployment meetings should be held monthly thereafter. The strategy process at the case company had three phases: review, development and acceptance and communication and implementation. Respectively, four phases of strategic planning were mentioned in the literature (Eppler and Platts, 2009): analysis, development, planning and implementation. The communication and continuity of the planning process (e.g., how often the plans are reviewed and revised) were not highlighted in the literature as they appeared in the case. The literature discusses how strategic plans should be adaptable to internal and external changes (Nordqvist and Melin, 2010) and that when there is a major change in strategic direction, strategic objectives should be renewed or revised (Bogsnes, 2008). As shown in the case studies, benefits (e.g., more accurate estimates, improved competencies, decreases work-in-progress) can be achieved at all levels of planning. Therefore, 
organisations should identify their own continuous planning practices (in relation to the planning onion framework) and at what levels to implement them in order to yield greater benefits.

In conclusion, as a somewhat new and insufficiently studied field, the literature on continuous planning is inadequate as it exists today, especially from a leagile development perspective. The current literature focuses mainly on a specific or single level of planning in an organisation while overlooking a wider perspective of continuous planning. In reference to the current literature, this study found that continuous planning is not being implemented throughout the entirety of organisations but rather applied only at a certain level of planning (e.g., release planning). In addition, product, portfolio, strategic and business planning were found to be of little concern to most agile teams. This study thus highlights that continuous planning should be examined from a broader perspective.

\subsection{Roadmapping}

The case studies reveal different timeframes for plans, with each timeframe directly related to the level of a plan in question. Continuous planning could be linked to long-term planning in only one of the cases, namely, case A, in which long-term plans projected three years ahead. Otherwise, the plans of the cases were reviewed on a quarterly or monthly basis at the strategy level and reviewed quarterly at the project level. However, team level plans were reviewed biweekly or weekly. Continuous planning was predominantly considered as short-term planning, though long-term planning (e.g., strategic, business, market and portfolio plans) was consistently considered at the higher levels of the enterprises.

In case $\mathrm{A}$, the timeframe for long-term strategy, roadmap and financial planning projected three years forward, including the current year. The strategic or financial frame for the following year was established prior to the turn of the year and thereafter, along with further plans and roadmaps, was reviewed on a quarterly and monthly basis. Similar to Rickards and Ritsert (2012) discussion, planning was found to be more detailed in early periods at the beginning of the year and less detailed in later periods of the year. The continuous planning in case A also related to the strategic roadmap layer presented by Cosner et al. (2007). Furthermore, as pointed out by Phaal and Muller (2009), the strategic planning horizon was found to consist of mid-term planning (roughly three years into the future), which highlights the broader direction and options that influence the short-term directions and plans. The short-term plans are in this case the quarterly and monthly reviews. In the case A, the planning strategy was divided into several roadmaps and as a business roadmap been one of them it defined company's current services and their status. Both the strategies and roadmaps of the organisations were made visible and available as public information via a tool called Jira, which allowed them to be reviewed in real-time.

In cases $\mathrm{B}$ and $\mathrm{C}$, the timeframe for continuous planning at the project level was three months. In case B, there was also visibility for the forthcoming six months, including deliverable(s) and scope. In case B, continuous planning did not remove the need for long-term planning, as resourcing and competency needs, as well as location and technology strategies, had to be considered at all times. Continuous planning at the project level in cases $\mathrm{B}$ and $\mathrm{C}$ related to the product roadmap layer presented by Cosner et al. (2007), as it mainly involved documenting performance and feature evolution, as 
well as presenting new products to the company and the world. According to Phaal and Muller (2009), short-term roadmaps are commonly set using one-year projections, yet in this case the timeframe was even shorter at three months. As highlighted by Phaal and Muller (2009), short-term roadmap is the most important layer because it includes tangible plans and committed actions. Furthermore, short-term roadmaps can be called the budget horizon, as resources need to be committed so that actions can be fulfilled. Case B also showed that the main tasks of project level planning involved making estimates in terms of scope and schedule and afterwards allocating resources. At the team level, the team of case B employed an even tighter planning cycle of continuous feature planning than case $\mathrm{C}$, which was done on a weekly basis to keep priorities and visibility up-to-date. Such priority planning in terms of features can be linked to the technology roadmap layer presented by Cosner et al. (2007), as it included expected R\&D products, their availability dates, motivating factors for R\&D and related information. Similarly, in case $\mathrm{C}$, the timeframe of continuous feature planning and development was set at the team level and involved two-week sprints, relating it to the same layer of enterprise roadmap development as case $\mathrm{B}$.

\subsection{Implications of continuous planning}

According to both the literature (e.g., Hope and Fraser, 2003; Rickards and Ritsert, 2012) and the empirical evidence of this study, the motivation for continuous planning arises from the fact that organisational plans increasingly cannot hold a fixed-focus of one year ahead anymore. Instead, plans need to be revised continuously according to consistent changes throughout the financial year. According to Rickards and Ritsert (2012), environmental changes trigger enterprise planning, not the financial year and thus planning frameworks need to be constantly adjusted to internal and external events. The interviews of case A speak to the fact that business environments are in constant flux. Thus, enterprises must adapt to change and look to benefit from the opportunities such changes may offer. Financial crises of the past decade have also caused companies to rethink approaches to planning and lead to their realisation of the importance of continuously planning both from an operational and financial perspective. Furthermore, an enterprise's internal problems (e.g., tensions between business and R\&D, as well as developers' long-term goals to achieve shorter planning cycles) were found to drive the need for continuous planning. In the workshops of case $C$, the development team realised that a time-boxed and static backlog for sprints was not the best way of working, as certain priority tasks would emerge during the sprints of which a standard model of working could not accommodate. The development team was interrupted with urgent tasks that forced it to consider new ways of managing its work. The team realised that its plans needed to evolve into a continuous planning approach.

Based on the meetings and the interview of case A, motivations to implement continuous planning were also found to stem from the need to improve transparency and knowledge sharing. Continuous visibility of development and operations was found to be needed in order to share and provide information more effectively. Operational transparency was found to increase the visibility of the performed work, plans and executed actions and development transparency was found to identify potential barriers to both the technological and cultural implementation of transparency and improving learning. With increased visibility, the need for continuous competency planning and development became apparent. It was found that competencies had to be able to adapt 
constantly and change via continuous analysis, development activities and evaluating the successfulness of actions.

The results of the empirical study confirm the findings of the literature (Cosner et al., 2007; Bogsnes, 2008; Koenigsaecker, 2009) that there are several components of continuous planning, including governance, leadership, transparency and competency development. Based on the empirical evidence of this study, the factors of continuous planning were found to include transparency and knowledge sharing, competency development and human aspects. While mentioned in the literature, governance and leadership issues were not found in the case studies, although it was pointed out in one of the cases that continuous planning had improved trust toward management.

\subsection{Validations and limitations of the research}

The case companies of this study are companies involved in IT product and service development that have transformed themselves into agile and lean enterprises. Each of the case companies is a large company with more than 1,000 employees. In order to establish the reliability of this study, triangulation of the study's qualitative data was performed as a validity procedure. The purpose of triangulation is to approach a studied object from various angles to provide an in-depth understanding of it (Runeson and Höst, 2009). The research results are based on three case studies in which data was gathered through interviews, a series of meetings and workshops and through the analysis of company-specific internal memos. The data (i.e., source) triangulation of this study served to strengthen its research results, as more than one data source was used and the same kind of data was collected on different occasions. The results of this study were also strengthened by observer triangulation. There were altogether two researchers involved in this research and the representatives of the case companies possessed various different roles. The research results are also bolstered via the triangulation of theory in his study, as alternative theories were discussed in the presentation of the research results.

The limitations of the study are as follows. The results of this study can only be applied to a certain extent to smaller companies, as all the study's case companies are considered to be large. Furthermore, the reliability of the results is weakened due to the fact that there was only one interviewee per company. The interviewees also possess subjective perspectives as to the questions asked concerning how the continuous planning process is viewed and defined within each case company. Lastly, the interviewees' answers do not speak to the collective opinions of others in the case companies.

\section{Conclusions}

This article has sought to draw attention to continuous planning, which is a relatively new and poorly studied field of research. During this paper's literature review, it was determined that there are only a few articles on continuous planning that can currently be found and few of these are written from an agile and lean development perspective. Thus, the main goal of the study was to increase continuous planning knowledge in terms of both the literature and empirical evidence. The empirical evidence of this study was 
formed drawn from the experiences of three case companies in terms of how they viewed and conducted continuous planning.

The research findings highlight the importance of continuous planning throughout an entire organisation including the elements of continuous planning (organisational planning, strategic planning and business planning) and their tight interrelation. Organisational planning serves to define a plan's organisational level and the timeframes of a plan, strategic planning serves to set an overall plan of an organisation and business planning serves to establish the budgeting frame of a plan. Furthermore, it has been here discussed that continuous planning may not be possible throughout an entire organisation and may only engage a certain level of planning. While continuous planning in agile and lean organisations commonly relates to release planning, this research has shed light on a broader perspective than this by defining continuous strategic and financial planning as well as continuous project and team-level planning. Companies seeking to develop or improve their continuous planning processes and practices should take each of the elements of continuous planning into account from a broader perspective to better understand the benefits it can yield for an organisation. The results of this research also reveal that companies should consider other aspects related to continuous planning, such as leadership, transparency and competency development in order to enable and succeed in their continuous planning efforts.

The motivation toward continuous planning has arisen from both external and internal challenges that companies face in today's volatile market environments. There is a clear need for continuous planning, as organisations face difficulties in developing long-term plans due to constant changes in their customer and market-bases, as well as in product and technology development. Moreover, recent financial crises have caused companies to rethink their approaches to planning and to realise the importance of continuous planning both from an operational and financial perspective. Continuous planning involves creating and revising plans as needed, typically more often than once a year. Based on the empirical findings of this study, the majority of long-term plans looked three years ahead. At the strategy, business, or project levels, plans were reviewed quarterly, whereas at the team level plans were reviewed biweekly or weekly. While continuous planning was mainly understood as short-term planning, this did not remove the need for long-term planning, as strategic, business, market and portfolio planning had to be constantly considered at the higher levels of each enterprise.

Future research on continuous planning should seek to collect more and broader case data from several different companies at different organisational levels. The cases of this study defined continuous planning at the strategy and financial levels, as well as project and team levels, yet continuous planning at business and portfolio levels was not discussed at length. Hence, continuous planning research should further examine these levels. Furthermore, future research could examine how continuous planning is conducted at each layer of each organisation in this research (e.g., how is continuous planning conducted at the product and team levels at the company of case A, which in this research focused mainly on the strategic and financial planning levels. Lastly, research methods other than interviews and workshops (e.g., observation) should be used to gather more in-depth knowledge of continuous planning in industries. The existence of broader case data would allow for comparing and contrasting the attributes of different cases. 


\section{References}

Abdulmalek, F.A. and Rajgopal, J. (2007) 'Analyzing the benefits of lean manufacturing and value stream mapping via simulation: a process sector case study', Int J Prod Econ, Vol. 107, No. 1, pp.223-236.

Abrahamsson, P., Salo, O., Ronkainen, J. and Warsta, J. (2002) Agile Software Development Methods: Review and Analysis, VTT Publications 478, VTT Technical report, Espoo.

Albright, R.E. (2003) 'A unifying architecture for roadmaps frames a value scorecard', Proceedings of the IEEE International Engineering Management Conference, pp.383-386.

Bellomo, S., Nord, R.L. and Ozkaya, I. (2013) 'A study of enabling factors for rapid fielding combined practices to balance speed and stability', 35th International Conference on Software Engineering (ICSE), pp.982-991.

Bogsnes, B. (2008) Implementing Beyond Budgeting: Unlocking the Performance Potential, John Wiley \& Sons, Hoboken, New Jersey.

Bryson, J.M. (2011) Strategic Planning for Public and Nonprofit Organizations: A Guide to Strengthening and Sustaining Organizational Achievement, Jossey-Bass, San Francisco, CA.

Butler, D. (2012) Business Planning: A Guide to Business Start-Up, Butterworth-Heinemann, Oxford.

Charette, R.N. (2003) Challenging the Fundamental Notions of Software Development, Cutter Consortium, Executive Rep, p.4, USA.

Cohn, M. (2006) Agile Estimation and Planning, Prentice Hall, NJ, US.

Cosner, R.R., Hynds, E.J., Fusfeld, A.R., Loweth, C.V., Scouten, C. and Albright, R. (2007) 'Integrating roadmapping into technical planning', Research-Technology Management, Vol. 50, No. 6, pp.31-48.

Creswell, J.W. (2003) Research Design: Qualitative, Quantitative, and Mixed Method Approaches, 2nd ed., Sage Publications, Thousand Oaks, California.

Easterbrook, S., Singer, J., Storey, M. and Damian, D. (2008) 'Selecting empirical methods for software engineering research', in Shull, F., Singer, J. and Sjøberg, D. (Eds.): Guide to Advanced Empirical Software Engineering, Springer, London.

Eppler, M.J. and Platts, K.W. (2009) 'Visual strategizing: the systematic use of visualization in the strategic-planning process', Long Range Plann., Vol. 42, No. 1, pp.42-74.

Fitzgerald, B. and Stol, K. (2014) 'Continuous software engineering and beyond: trends and challenges', Proceedings of the 1st International Workshop on Rapid Continuous Software Engineering, pp.1-9.

Heikkilä, V.T., Paasivaara, M., Lassenius, C. and Engblom, C. (2013) Continuous Release Planning in A Large-Scale Scrum Development Organization at Ericsson, Springer, Berlin Heidelberg.

Highsmith, J. (2002) Agile Software Development Ecosystems, Addison-Wesley, Boston.

Hope, J. and Fraser, R. (2003) Beyond Budgeting: How Managers Can Break Free from the Annual Performance Trap, Harvard Business School Press, Boston, Massachusetts.

Järvinen, J., Huomo, T., Mikkonen, T. and Tyrväinen, P. (2014) 'From agile software development to mercury business', Proceedings of the 5th International Conference (ICSOB), Springer, pp.58-71.

Järvinen, P. (2001) On Research Methods, Opinpajankirja, Tampere, Finland.

Kameoka, A., Kuwahara, T. and Li, M. (2003) 'Integrated strategy development: an integrated roadmapping approach', Proceedings of the Portland International Conference on Management of Engineering and Technology (PICMET), pp.370-379.

Kappel, T.A. (2001) 'Perspectives on roadmaps: how organisations talk about the future', J. Prod. Innovation Manage., Vol. 18, No. 1, pp.39-50.

Kettunen, P. (2009) 'Adopting key lessons from agile manufacturing to agile software product development - a comparative study', Technovation, Vol. 29, No. 6, pp.408-422. 
Koenigsaecker, G. (2009) Leading the Lean Enterprise Transformation, CRC Productivity Press Taylor \& Francis Group, USA.

Kostoff, R.N. and Schaller, R.R. (2001) 'Science and technology roadmaps', IEEE Trans. Eng. Manage., Vol. 48, No. 2, pp.132-143.

Leffingwell, D. (2007) Scaling Software Agility: Best Practices for Large Enterprises, AddisonWesley, Boston, MA.

Leffingwell, D. (2011) Agile Software Requirements: Lean Requirements Practices for Teams, Programs, and the Enterprise, Pearson Education, Inc., Boston, MA, USA.

Lehtola, L., Kauppinen, M. and Vähäniitty, J. (2007) 'Strengthening the link between business decisions and RE: long-term product planning in software product companies', 15th IEEE International Requirements Engineering Conference (RE' 07), pp.153-162.

Lehtola, L., Kauppinen, M., Vähäniitty, J. and Komssi, M. (2009) 'Linking business and requirements engineering: is solution planning a missing activity in software product companies?', Requirements Engineering, Vol. 14, No. 2, pp.113-128.

Mavengere, N.B. (2013) 'Information technology role in supply chain's strategic agility', International Journal of Agile Systems and Management, Vol. 6, No. 1, pp.7-24.

Middleton, P. and Sutton, J. (2005) Lean Software Strategies: Proven Techniques for Managers and Developers, Productivity Press, New York.

Middleton, P., Flaxel, A. and Cookson, A. (2005) 'Lean software management case study: Timberline inc', Proceedings of the 6th International Conference on Extreme Programming and Agile Processes in Software Engineering (XP), pp.1-9.

Myers, K.L. (1999) 'CPEF: a continuous planning and execution framework', AI Magazine, Vol. 20, No. 4, pp.63-69.

Naylor, J.B., Mohamed, M.N. and Berry, D. (1999) 'Leagility: integrating the lean and agile manufacturing paradigms in the total supply chain', Int J Prod Econ, Vol. 62, No. 1, pp.107-118.

Nordqvist, M. and Melin, L. (2010) 'The promise of the strategy as practice perspective for family business strategy research', Journal of Family Business Strategy, Vol. 1, No. 1, pp.15-25.

Olsson, H.H., Bosch, J. and Alahyari, H. (2013) 'Towards R\&D as innovation experiment systems: a framework for moving beyond agile software development', IASTED MulticonferencesProceedings of the IASTED International Conference on Software Engineering, SE 2013, pp.798-805.

Overby, E., Bharadwaj, A. and Sambamurthy, V. (2005) 'A framework for enterprise agility and the enabling role of digital options', International Working Conference on Business Agility and Information Technology Diffusion, Vol. 180, pp.295-312.

Petersen, K. (2010) 'Is lean agile and agile lean? A comparison between two software development paradigms', in Dogru, A.H. and Bicer, V. (Eds.): Modern Software Engineering Concepts and Practices: Advanced Approaches, IGI Global, USA.

Petersen, K. and Wohlin, C. (2010) 'Software process improvement through the lean measurement (SPI-LEAM) method', J. Syst. Software, Vol. 83, No. 7, pp.1275-1287.

Phaal, R. and Muller, G. (2009) 'An architectural framework for roadmapping: towards visual strategy', Technological Forecasting and Social Change, Vol. 76, No. 1, pp.39-49.

Phaal, R., Farrukh, C. and Probert, D. (2005) 'Developing a technology roadmapping system', Proceedings of the Portland International Conference on Management of Engineering and Technology (PICMET), pp.99-111.

Poppendieck, M. and Poppendieck, T. (2003) Lean Software Development: An Agile Toolkit, Addison-Wesley, Boston, MA.

Poppendieck, M. and Poppendieck, T. (2007) Implementing Lean software development: From Concept to Cash, Addison-Wesley Professional, Massachusetts, USA.

Radnor, Z. and Walley, P. (2008) 'Learning to walk before we try to run: adapting lean for the public sector', Public Money and Management, Vol. 28, No. 1, pp.13-20. 
Rickards, R.C. and Ritsert, R. (2012) 'Rediscovering rolling planning: controller's roadmap for implementing rolling instruments in SMEs', Procedia Economics and Finance of 2nd Annual International Conference on Accounting and Finance (AF 2012) and Qualitative and Quantitative Economics Research (QQE 2012), Vol. 2, pp.135-144.

Ruhe, G. (2010) Product Release Planning: Methods, Tools and Applications, CRC Press, USA.

Runeson, P. and Höst, M. (2009) 'Guidelines for conducting and reporting case study research in software engineering', Empirical Software Engineering, Vol. 14, No. 2, pp.131-164.

Shalloway, A., Beaver, G. and Trott, J.R. (2009) Lean-Agile Software Development: Achieving Enterprise Agility, Addison-Wesley Professional, Upper Saddle River, NJ.

Suomalainen, T., Salo, O., Abrahamsson, P. and Similä, J. (2011) 'Software product roadmapping in a volatile business environment', J. Syst. Software, Vol. 84, No. 6, pp.958-975.

Te Brömmelstroet, M. (2013) 'Performance of planning support systems: what is it, and how do we report on it?', Comput., Environ. Urban Syst., September, Vol. 41, pp.299-308.

Van de Weerd, I., Bekkers, W. and Brinkkemper, S. (2010) 'Developing a maturity matrix for software product management', Proceedings of the 1st International Conference on Software Business (ICSOB 2010), pp.76-89.

Van Oosterhout, M., Waarts, E. and van Hillegersberg, J. (2005) 'Assessing business agility: a multi-industry study in the Netherlands', Business Agility and Information Technology Diffusion, Vol. 180, pp.275-294.

Wareham, T.L. and Majka, A.J. (2003) Best Practice Financing, Kaufman Hall White Paper, Kaufman, Hall \& Associates, Northfield, IL.

Westkamper, E. and von Briel, R. (2001) 'Continuous improvement and participative factory planning by computer systems', CIRP Annals-Manufacturing Technology, Vol. 50, No. 1, pp.347-352.

Womack, J.P. and Jones, D.T. (2003) Lean Thinking: Banish Waste and Create Wealth in Your Corporation, Revised and Updated, Free Press, USA.

Yin, R.K. (1994) Applied Social Research Methods Series Vol 5; Case Study Research: Design and Methods, 2nd ed. Sage Publications, Inc. Yin, R.K, Thousand Oaks, California. 